\title{
Tumor abdominal desmoplásico de células pequeñas y redondas
}

\section{Desmoplastic small round cell abdominal tumor}

\author{
Christian M. Chavarría-Caldas,' Maximandro P. Terán-Vásquez,' \\ Pedro A. Páucar-Pérez, ${ }^{2}$ Rocío M. Carrasco-Burgos ${ }^{2}$ y \\ José L.Arenas-Gamio ${ }^{3}$
}

Chavarría-Caldas CM, Terán-Vásquez MP, PáucarPérez PA, Carrasco-Burgos RM, Arenas-Gamio JL. Tumor abdominal desmoplásico de células pequeñas y redondas. Rev Soc Peru Med Interna. 2019;32(3):103106.

https://doi.org//0.36393/spmi.v32i3.479

\section{RESUMEN}

Se presenta el caso de un joven de 21 años, que cursa con dolor y aumento de volumen abdominal debido a una tumoración intraabdominal de crecimiento rápido. La biopsia percutánea del tumor reveló un tumor desmoplásico de células pequeñas y redondas.

Palabras clave. tumor intraabdominal, tumor desmoplásico, células redondas y pequeñas.

\section{ABSTRACT}

A 21 year-old young man presented with pain and increased abdominal volume due to a rapid-growing intra-abdominal tumor. Percutaneous biopsy of the tumor revealed a desmoplastic tumor of small round cells.

KEYwords. intra-abdominal tumor, desmoplastic tumor, small and round cells.

\section{INTRODUCCIÓN}

El tumor desmoplásico de células pequeñas y redondas (TDCPR) es una neoplasia poco frecuente, de carácter agresivo, con una mayor incidencia en el sexo masculino, en la segunda y tercera década de la vida. ${ }^{1,2}$

Este tumor único muestra una translocación cromosómica t $(11 ; 22)$ (p13; q12), característica que involucra la fusión de los genes del sarcoma de Ewing y del tumor de Wilms, con características patológicas únicas. ${ }^{3}$

I Médico residente de Medicina interna. Hospital Nacional Guillermo Almenara Irigoyen (HNGAl), Lima.

2 Médico internista. HNGAI, Lima.

3 Médico patólogo. Servicio de Anatomía Patológica, HNGAI, Lima.
Afecta principalmente a las membranas serosas, predominantemente al peritoneo, donde un $62 \%$ se ubica en el abdomen y el $38 \%$ en la pelvis. Además, se describen en otras localizaciones primarias como en la región paratesticular y escroto, fosa posterior y proporción petrosa del hueso temporal, órbita, riñón, hueso, tejidos blandos y otros órganos abdominales.-8

$\mathrm{Su}$ manifestación clínica va depender del sitio de origen. En la presentación intraabdominal, se manifiesta con dolor y distensión abdominal, que pueden estar acompañados de extensos implantes tumorales. ${ }^{9}$

A nivel histológico se caracteriza por la presencia de nidos de células tumorales pequeñas y redondas en un estroma fibroso y desmoplásico. ${ }^{2}$ La expresión inmunohistoquímica es característica, ya que expresa en forma constante marcadores epiteliales, musculares y neurales, y hasta en $91 \%$ de los casos son positivos al tumor de Wilms. ${ }^{10}$

El diagnóstico presenta un pronóstico sombrío a pesar de las estrategias terapéuticas multimodales agresivas asociadas con una tasa de mortalidad de hasta $70 \%$ dentro de los tres años del diagnóstico. ${ }^{11}$ 


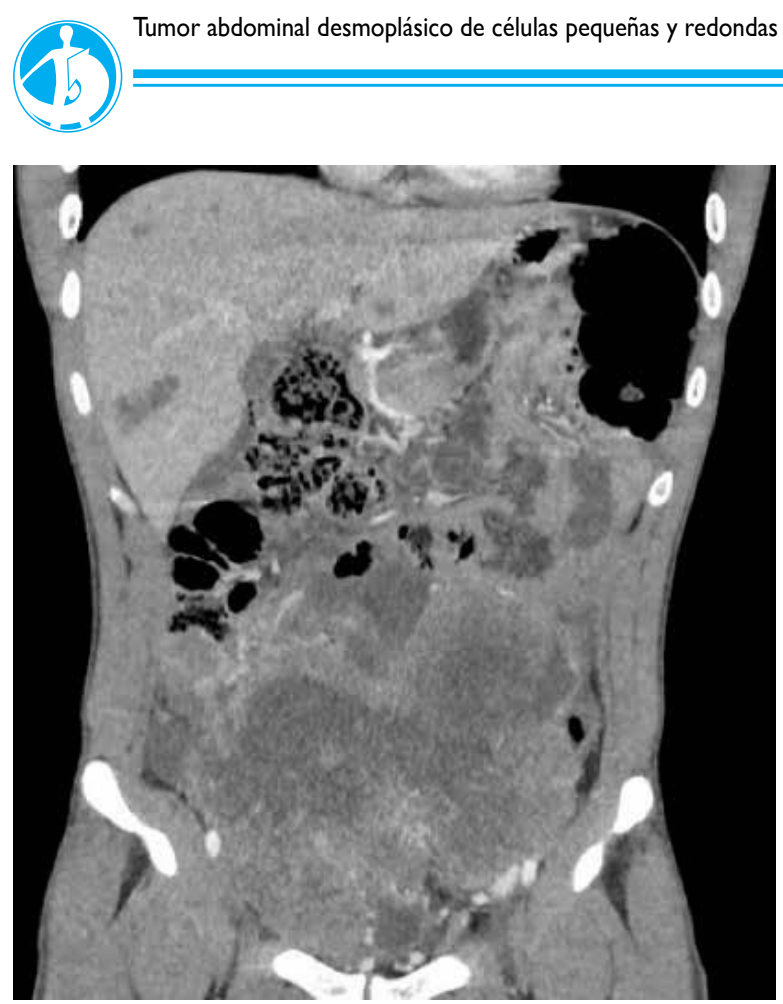

Figura I. Tumoración abdominopélvica, de densidad heterogénea, de $12 \times 17 \mathrm{~cm}$, de bordes lobulados; imágenes hipodensas en hígado, sugerentes de metástasis.

\section{PRESENTACIÓN DEL CASO}

Paciente varón de 21 años, sin antecedentes patológicos de importancia, con un tiempo de enfermedad de dos meses caracterizado por dolor abdominal y aumento del perímetro abdominal progresivo, ingresando por el servicio de Emergencia con hiporexia, náuseas y vómitos. En la exploración física abdominal, se palpaba una masa en hemiabdomen inferior, de $15 \mathrm{~cm}$ x $20 \mathrm{~cm}$, de consistencia incrementada, no móvil, sin otros hallazgos.

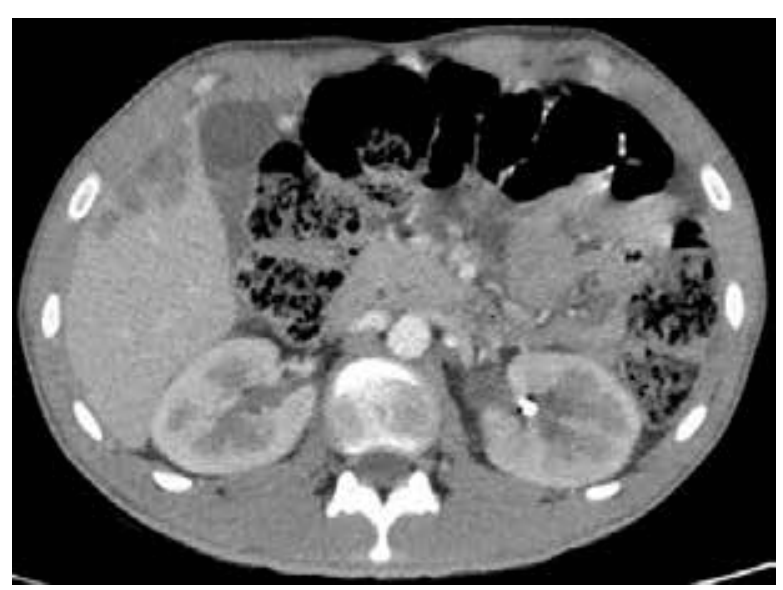

Figura 2. Hidronefrosis bilateral secundaria a compresión tumoral, además de lesiones hipodensas en hígado, sugerentes de metástasis.

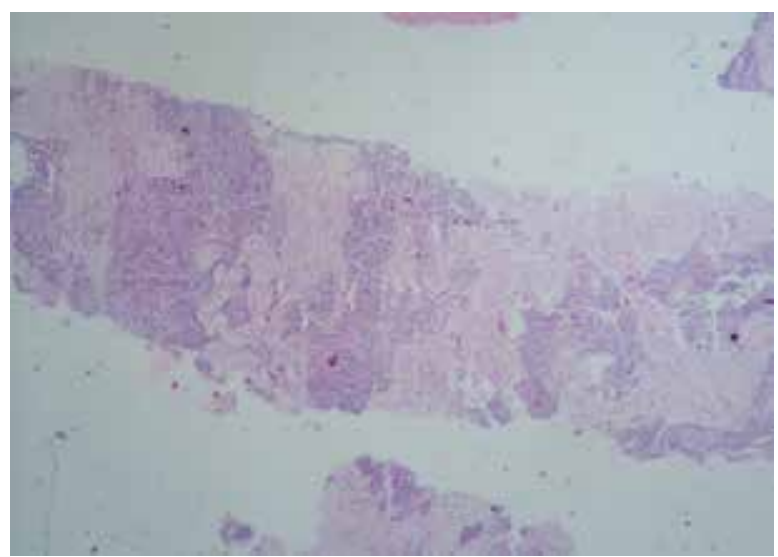

Figura 3.Tumoración abdominal: nidos e islas de células pequeñas con escaso citoplasma, rodeadas por un estroma desmoplásico prominente.

En los exámenes auxiliares, se evidenció incremento de la creatinina $(1,8 \mathrm{mg} / \mathrm{dL})$, sin alteración en los demás exámenes. Se realizó tomografía de abdomen y pelvis, donde se evidenció masa intraabdominal de $12 \times 17 \times 15 \mathrm{~cm}$, de densidad heterogénea, bordes mal definidos, que ocasionaba compresión extrínseca y condicionaba hidroureteronefrosis bilateral, sin evidencia de infiltración a estructuras vecinas adyacentes, y con lesiones nodulares múltiples en hígado, sugerentes de metástasis (Figuras 1 y 2).

La biopsia percutánea de la tumoración abdominal mostró la presencia de nidos e islas de células pequeñas y redondas en un estroma desmoplásico (Figura 3), con núcleos de cromatina homogénea, con alto índice mitótico y necrosis (Figura 4), consistente con neoplasia maligna de células redondas pequeñas de alto grado.

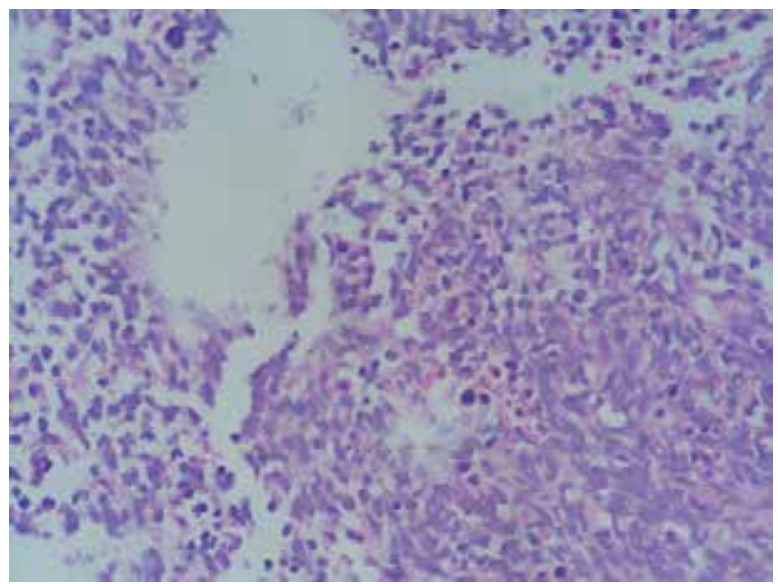

Figura 4.A mayor aumento: células redondas, ovales, con núcleos de cromatina homogénea, con nucléolo poco visible, alto índice mitótico y necrosis. 


\section{DISCUSIÓN}

El TDCPR es una neoplasia de origen mesenquimal rara, muy agresiva y que se extiende a lo largo de las superficies peritoneales en la mayoría de los pacientes. Además, ${ }^{4}$ pertenece a la familia de las neoplasias conocidas como tumores de células redondas y azules, los cuales incluyen neuroblastoma, rabdomiosarcoma, linfoma no Hodgkin, sarcoma de Ewing, tumor de Wilms y tumor neuroectodérmico primitivo y sarcoma sinovial anaplásico. ${ }^{9,10}$

Fue descrito por primera vez como una entidad clínico patológica, por Gerald y Rosai, en 1989. Hasta el momento, unos 450 casos han sido reportados en la literatura. ${ }^{12}$

El TDCPR afecta predominantemente a pacientes jóvenes blancos, adolescentes y adultos jóvenes, y con mayor frecuencia en pacientes masculinos, con una relación de varón a mujer de 3:1 a 9:1, según diferentes estudios. ${ }^{13}$

La mayoría de los pacientes manifiestan dolor y distensión abdominales y presentan tumor abdominal palpable, así como ocurrió en el paciente del caso presentado. A medida que el tumor crece, ejerce efecto de masa y se puede asociar a síntomas como estreñimiento, obstrucción intestinal, hidronefrosis, dolor lumbar o síntomas relacionados con sitios raros extraperitoneales del tumor., ${ }^{9,14}$

Es un tumor localmente agresivo, que invade $\mathrm{y}$ comprime estructuras vecinas (gastrointestinales y genitourinarias). Puede causar hidronefrosis secundaria a compresión del sistema urinario, como ocurrió en nuestro paciente, que es poco frecuente y ha sido documentada en escasos reportes de casos. Asimismo, puede cursar con ascitis, invasión linfática y dar metástasis hematógena, sobre todo, a nivel hepático y, en menor frecuencia, a pulmón. ${ }^{14}$

El rasgo característico de las imágenes de TDCPR es la presencia de múltiples masas de contorno lobulado bien definidos, partes blandas hiperdensas y heterogéneas, con áreas de hipodensidad relacionadas a focos de necrosis y hemorragia, que afectan a la cavidad peritoneal y sin un órgano de origen definido. Por ejemplo, en un estudio, 85 pacientes (90\%) presentaron masas multifocales, nodulares, omentales y peritoneales difusas, o una combinación de estas masas. Las masas variaban en tamaño de 2 a $27 \mathrm{~cm}$ en su dimensión máxima (mediana de $12 \mathrm{~cm}$ ); 32 pacientes (34\%) tenían metástasis hepáticas, 3 pacientes manifestaron hidronefrosis bilateral causada por una gran masa o masas pélvicas obstructivas, 49 pacientes (52\%) tuvieron afectación retroperitoneal en forma de implantes, extensión tumoral o afectación nodal. ${ }^{15}$

En el estudio histológico presenta un patrón de células pequeñas, redondas, con núcleos hipercromáticos, escaso citoplasma y abundante mitosis, que se disponen en nidos, cordones y áreas solidas bien delimitadas, sobre un estroma desmoplásico. ${ }^{16}$

El estudio inmunofenotípico se caracteriza por presentar un patrón con expresión para marcadores epiteliales, mesenquimales y neuronales. ${ }^{16}$ En el presente caso, los marcadores de inmunohistoquímica panqueratina, EMA y vimentina presentan positividad escasa multifocal; y el antígeno común leucocitario (ACL), S-100 y sinaptofisina fueron negativos. El cuadro histológico y los marcadores de inmunohistoquímica fueron compatibles con el diagnóstico de TDCPR.

Con base en reportes de casos, sobre todo en edad pediátrica, es muy difícil determinar las mejores opciones de tratamiento. El paradigma óptimo de manejo contempla la citorreducción quirúrgica mayor al $90 \%$ del tumor asociado con quimioterapia multimodal, los cuales mejorarían la supervivencia. ${ }^{17}$

La resección quirúrgica es efectiva, principalmente en TDCR sin enfermedad periférica y extraabdominal, con una mediana de supervivencia de 34 meses, además de mejorar los síntomas compresivos. ${ }^{18}$

El régimen quimioterápico más eficaz todavía se debate. La mayoría de las combinaciones se basan en agentes alquilantes. El esquema estándar P6 (ciclofosfamida, doxorrubicina, vincristina, ifosfamida y etopósido), según estudios, determina una supervivencia de 19 meses, aunque con elevadas tasas de toxicidad tanto renal como hematológica. Recientes estudios comparativos plantean un esquema menos tóxico y tan beneficioso como el anterior: VAIA (ifosfamida, vincristina, adriamicina D, carboplatino y actinomicina D). ${ }^{19}$

Un esquema de citorreducción más quimioterapia intraperitoneal hipertérmica (CRS/HIPEC) se vislumbra como una opción terapéutica con morbilidad perioperatoria aceptable. Sin embargo, el impacto a largo plazo sigue siendo mal definido. ${ }^{17}$

La radioterapia de intensidad modulada como terapia coadyuvante no presenta resultados convincentes. ${ }^{18}$ 
Los regímenes de terapia más recientes que utilizan anticuerpos monoclonales tienen éxito en pequeñas series de pacientes. Se han identificado marcadores moleculares, como la molécula inmunomoduladora B7H3, que solo se expresa en células tumorales y otros antígenos como GD2, IGF1R, mTOR36 y receptores de andrógenos que son susceptibles de modificación, con resultados alentadores en estudios de fases I y II. Por otro lado, la reactividad cruzada con tejidos normales o inaccesibilidad de los anticuerpos monoclonales, debido a la localización de antígenos en el núcleo o citoplasma de las células tumorales, hace más difícil sostener períodos libres de enfermedad. ${ }^{20}$

El tumor desmoplásico intraabdominal de células pequeñas y redondas es un tumor poco frecuente, altamente agresivo, de complejidad diagnóstica, que se manifiesta con síntomas inespecíficos, por lo que se debe tener en cuenta en pacientes jóvenes con tumoración intraabdominal.

\section{REFERENCIAS BIBLIOGRÁFICAS}

I. Gerald WL, Rosai J. Desmoplasic small cell tumour with divergent differentiation. Ped Pathol. 1989;9:177-183.

2. Gerald WL, Miller HK, Battifora H, Miettinen M, Silva E, Rosai J. Intraabdominal desmoplastic small round cell tumor. Am J Surg Pathol. 1991; 16:499-513.

3. GeraldWL, Rosai J, Ladanyi M. Characterization of the genomic breakpoint and chimeric transcripts in the EWS-WTI gene fusion of desmoplastic small round cell tumor. Proc Natl Acad Sci USA. 1995;92:1028-1032.

4. Cumming OW, Ulbright TM, Young RH, Dei Tos AP, Fletcher CDM, Hull MT. Desmoplastic small round cell tumor of the paratesticular region. Am J Surg Pathol. 1997;21:219-225.

5. Tison, V, Cesaroli S, Morigi F, Landanyi M, Gerald W, Rosai J. Intracraneal desmoplastic small cell tumor: report of a case. Am J Surg Pathol. 1996; 20:112-II7.

6. Yoon M,Desai K, Fulton R, Bucci K, Russin M,Conway, R, et al.Desmoplastic small round cell tumor: a potentially lethal neoplasm manifesting in the orbit with associated visual symptoms. Arch Oph. 2005; 123:565-7.

7. Su MC, Jeng YM, Chu YC. Desmoplastic small round cell tumor of the kidney (case report).Am J Surg Pathol. 2004;28:I379-I383.
8. Adsay V, Cheng J, Athanasian E, Gerald W, Rosai J. Primary desmoplastic small round cell tumor of soft tissues and bone of the hand. Am J Surg Pathol. 1999;23: |408-1413.

9. Tejerina González E, Corbacho Cuevas C, López García A, Bellas Menéndez $C$, Sánchez Turrión $V$, Sánchez Ruiz $A$, et al. Tumor intraabdominal desmoplásico de células pequeñas y redondas. Revisión de la literatura a propósito de un caso con estudio citológico, histopatológico, inmunohistoquímico y molecular. Oncologia (Barc). 2007;30:25-3I.

10. Lae M, Roche P, Jin L, Lloyd R, Nascimento A. Desmoplastic small round cell tumor: a clinicopathologic, immunohistochemical, and molecular study of 32 tumors. Am J Surg Pathol. 2002;26:823-835.

II. Hayes-Jordan A, Green HL, Lin H, et al. Complete cytoreduction and HIPEC improves survival in desmoplastic small round cell tumor. Ann Surg Oncol. 2014;21:220-224.

12. Bulbul A, Fahy BN, Xiu J, et al. Desmoplastic small round blue cell tumor: a review of treatment and potential therapeutic genomic alterations. Sarcoma. 2017;2017:1278268. doi: 10.1 155/2017/1278268.

13. lyer RS, Schaunaman G, Pruthi S, Finn LS. Imaging of pediatric desmoplastic small-round-cell tumor with pathologic correlation. Curr Probl Diagn Radiol. 2013;42:26-32.

14. Santos JA, Martín MJ, Flores T, De Castro FJ. Tumor desmoplasico intrabdominal de células pequeñas redondas: hallazgos en imágenes y anatomía patológica. Rev Chi Rad. 2009; I5:I23-127.

I5. Morani AC, Bathala TK, Surabhi VR, Yedururi S, Jensen CT, Huh WW, et al. Desmoplastic small round cell tumor: Imaging pattern of disease at presentation.AJR. 2019;2I2:WI-WIO.

16. Brindis M, Villalobos A, De León B, Bornstein L, Rodriguez R, Carvajal $A$, et al. Tumor desmoplásico de células pequeñas y redondas. Estudio multiinstitucional clinicopatológico e inmunohistoquímico de 8 casos. Cancerología. 2007;2:67-74.

17. Stiles ZE, Murphy AJ, Anghelescu DL, Brown CL, Davidoff AM, Dixson $\mathrm{PV}$, et al. Desmoplastic small round cell tumor: Long-term complications after cytoreduction and hyperthermic intraperitoneal chemotherapy. Ann Surg Oncol. 2018; DOI 10.1245/s 10434-019-07339-2

18. Ashwin A. Kallianpur, Nootan K. Shukla, Suryanarayan V.S. Updates on the multimodality management of desmoplastic small round cell tumor.J Surg Oncol. 2012;105:617-621.

19. Scheer M, Vokuhl C, Blank B, Hallmen E, von Kalle T, Münter M, et al. Desmoplastic small round cell tumors: Multimodality treatment and new risk factors. Cancer Med. 2019;8:527-542.

20. Hayes-Jordan A, LaQuaglia MP, Modak S. Management of desmoplastic small round cell tumor. Semin Pediatr Surg. 2016;25(5):299-304.

Correspondencia: Christian M. Chavarría-Caldas christian_cc04@hotmail.com

FECHA DE RECEPCIÓN: 3 de julio de 2019.

FECHA DE ACEPTACIÓN: I5 de julio de 2019. 